\section{Public Health} Genomics
Public Health Genomics 2010;13:495-503

DOI: $\underline{10.1159 / 000294469}$
Received: June 16, 2009

Accepted after revision: November 17, 2009

Published online: April 9, 2010

\title{
Prevalence of Family History of Breast, Colorectal, Prostate, and Lung Cancer in a Population-Based Study
}

\author{
P.L. Mai ${ }^{\mathrm{a}} \quad$ L. Wideroff ${ }^{c} \quad$ M.H. Greene ${ }^{\mathrm{a}} \quad$ B.I. Graubard ${ }^{\mathrm{b}}$ \\ ${ }^{a}$ Clinical Genetics Branch and ${ }^{b}$ Biostatistics Branch, Division of Cancer Epidemiology and Genetics, \\ National Cancer Institute, and ' Division of Epidemiology, Services and Prevention Research, National Institute \\ on Drug Abuse, National Institutes of Health, Bethesda, Md., USA
}

\section{Key Words}

Breast cancer $\cdot$ Colorectal cancer $\cdot$ Family history $\cdot$ Lung cancer $\cdot$ Prevalence $\cdot$ Prostate cancer $\cdot$ Telephone survey

\section{Abstract}

Background: A positive family history is a known risk factor for several cancers; thus, obtaining a thorough family cancer history is essential in cancer risk evaluation and prevention management. Methods: The Family Health Study, a telephone survey in Connecticut, was conducted in 2001. A total of 1,019 participants with demographic information and family cancer history were included in this study. Prevalence of a positive family history of breast, colorectal, prostate, and lung cancer for first- and second-degree relatives was estimated. Logistic regression was used to compare prevalence by demographic factors. Results: A positive family history among first-degree relatives was reported by $10.9 \%$ (95\% Confidence Interval, $\mathrm{Cl}=8.8-13.3$ ) of respondents for breast cancer, $5.1 \%(95 \% \mathrm{Cl}=3.9-6.7)$ for colorectal cancer, $7.0 \%$ $(95 \% \mathrm{Cl}=5.2-9.4)$ for prostate cancer, and $6.4 \%(95 \% \mathrm{Cl}=$ 4.9-8.3) for lung cancer. The reported prevalence of family history of specific cancers varied by sex, age and race/ethnic-

\section{KARGER}

Fax +4161306 1234

E-Mail karger@karger.ch

www.karger.com (c) 2010 S. Karger AG, Basel

Accessible online at: www.karger.com/phg ity of the respondents. Conclusion: Family history prevalence for 4 of the most common adult solid tumors is substantial and the reported prevalence varied by respondent characteristics. Additional studies are needed to evaluate tools to promote accurate reporting of family history of cancer.

Copyright $\odot 2010$ S. Karger AG, Basel

\section{Introduction}

Cancer is the most common cause of death among individuals younger than 85 years in the U.S. Approximately 1.44 million new cases of invasive, non-skin cancers are estimated to have occurred in 2008 [1]. Site-specific cancer risk factors are not completely established and vary widely; however, a positive family history is a known risk factor for most malignancies [2-9]. Hereditary cancer syndromes, usually characterized by significant family history, account for only a small percentage of all cancer cases [10]. Individuals with a family history that is positive for certain cancers, but not consistent with a hereditary cancer syndrome, are at moderately increased risk of 
developing those cancers. Thus, a comprehensive family history is an important tool in cancer risk assessment and prevention management $[11,12]$. However, family history has not been fully utilized, particularly in public health and prevention [13-15]. For common cancers such as breast, prostate, lung, and colorectal cancers, even a small fraction of risk due to family history can result in a substantial number of cancers being attributable to familial factors at the population level [5].

Despite the potential importance of family history of cancer information in public health, few studies that characterize prevalence for the general population have been published and most have reported only prevalence among first-degree relatives [16-19]. Moreover, reported family history prevalence varies by cancer type and socioeconomic factors such as race/ethnicity, age, gender, and income [18-20]. We have previously conducted a representative random digit dialing survey, the Family Health Study (FHS), in Connecticut (CT) to assess the quality of self-reported family history of cancer and to estimate the population prevalence of family history of several common cancers and its association with sociodemographic factors. Here we present the prevalence of female breast, colorectal, prostate, and lung cancer among first-degree relatives (FDR), second-degree relatives (SDR) and combined first- and second-degree relatives (F/SDR), as reported by survey respondents.

\section{Methods}

\section{Survey Methods}

The FHS was conducted in 2001 after the study protocol was approved by the Institutional Review Boards at the National Cancer Institute and Westat. Study details have been described elsewhere [21]. In brief, a sample of 11,982 CT telephone numbers was selected by random digit dialing [22] and 2,418 households with eligible members were identified. Eligible subjects were aged 2564 years, had been raised by at least one biological relative and had parents, or at least one parent and one sibling, born or raised in the U.S. or Puerto Rico. In households with multiple eligible members, the most recent birthday was used to select one for the survey. A total of 1,380 individuals completed the first of 2 sequential computer-assisted telephone interviews for a Council of American Survey Organizations (CASRO) response rate of $70 \%$ [23].

During the first interview, respondents were asked to provide vital status, current age or birth year, age or year of death if deceased, and history of up to 3 primary cancer diagnoses for each of all biological FDR (parents, siblings and children) and SDR (grandparents, uncles, aunts, nieces, and nephews). Grandchildren were excluded from the study since the prevalence of cancer in this group of young individuals was expected to be very low. Age and personal cancer history for the respondents were also obtained at the first interview. The second telephone interview was conducted within one month of the first. In the second interview, respondent demographic information (i.e. race/ethnicity, education level and income) was obtained, along with contact information and consent to contact sampled relatives. Of the original 1,380 respondents, 1,019 subsequently completed the second interview (CASRO response rate of $74 \%$ ).

\section{Cancer History Ascertainment}

The respondents were asked if each of their enumerated relatives ever had cancer (response categories: yes, no, don't know). If the response was yes, the type of cancer or specific part of the body where the cancer started was obtained. Interviewers recorded verbatim responses to the cancer site question, as well as other details that respondents volunteered about metastases, co-morbidities and medical procedures. Age or year at cancer diagnosis was also obtained. If the age or year at diagnosis was not known, respondents were asked to report ten-year age or year ranges in which the cancer was diagnosed or whether the cancer was diagnosed before or after the age of 50 years. ICD-9 disease codes [24] were assigned by nosologists based on the verbatim cancer reports and were independently reviewed for accuracy (L.W.). All reports that contained extraneous or vague information were classified through consensus review (M.H.G., L.W.) and excluded if deemed to be not consistent with a diagnosis of cancer. For this report, cases that were determined to be consistent with invasive cancer of the breast, prostate, lung, colon, or rectum were included. For colorectal cancer, we also included cases reported as 'intestinal cancer' or 'stomach or intestinal cancer', under the assumption that most intestinal cancers were colorectal. Family history was defined as positive for a certain cancer in a relatedness category (FDR, SDR, or F/SDR) if at least one relative in that category was reported to have had the cancer.

\section{Statistical Analyses}

The sample of 1,019 respondents who completed the second interview was included in this analysis. Each respondent was assigned a sampling weight to adjust for differential selection probabilities and rates of nonresponse and for post-stratification, which constrained the weighted sample from the FHS to approximate the age and gender distribution of U.S. Census values for CT. A replicate weight approach based on the delete-one jackknife method was used in standard error estimation [25] to account for additional variation from intra-familial correlations resulting from one respondent reporting about multiple relatives and the reduced variation due to the adjustments made to the sample weights. All analyses were weighted by the sample weights. SAS v.9.1 (SAS Institute Inc., 2004) and callable SUDAAN v.9.0 (Research Triangle Research, 2004) statistical software were used to conduct the analyses and estimate the standard errors. All reported $\mathrm{p}$ values are two-sided.

Seventy-four relatives with missing information on gender or cancer history were excluded, resulting in a final analytic cohort of 20,504 relatives $(6,242$ FDR and 14,262 SDR, excluding grandchildren). Weighted percentages were calculated to determine the proportion of respondents with a history of female breast, colorectal, prostate, or lung cancer among their FDR, SDR and all relatives combined. Weighted logistic regression analyses were conducted to identify respondent characteristics associated with a family history of each cancer type. The statistical testing for sig- 
nificant prediction of family history by each ordinal categorical variable (age, education and income) was accomplished by treating it as a continuous variable in a test for linear trend in the logistic regression with all the other variables included as nominal categorical covariates. Global Wald F tests were used to test for statistical significance of the nominal variables (gender, race and personal history of any cancer) [26].

In the logistic regression models with all covariates treated as nominal categorical variables, predictive margins were calculated to adjust prevalence estimates by gender, personal history of any cancer (the number of respondents with a personal history of breast, colorectal, prostate, or lung cancer was too small to permit site-specific correlations with family history for the same cancer), race/ethnicity (non-Hispanic white, non-Hispanic black, Hispanic, and others), age group (25-34, 35-44, 45-54, and 55-64), education (high school graduate or less, some college or college graduate, including vocational and technical school, and post-graduate), income ( $\leq 20,000,20,001-40,000,40,001-60,000$, $60,001-80,000$, and $>80,000$ ), and total number of relatives (total number of female relatives only was used in the model for breast cancer and total number of male relatives only was used in the model for prostate cancer). The predictive margin for a given group represents the predicted proportion if everyone in the sample had been in that group while taking into account the covariates distribution of the sample [27] and is a useful alternative to odds ratios for illustrating differences in proportions between groups.

\section{Results}

The cohort consisted of 1,019 respondents who reported a total of 20,504 F/SDR, of whom 12,612 (61.5\%) were living, 7,598 (37.1\%) were deceased, and 294 (1.4\%) had unknown vital status. The respondent characteristics have been described previously [21]. In brief, compared with the CT samples from the 2001 Current Populations Survey, the respondents in the FHS had similar age, gender and income distributions, fewer non-whites, and more individuals with either post-graduate education or high school or less. Overall, the mean number of relatives reported per respondent was 6.03 (95\% confidence interval, $\mathrm{CI}=5.86-6.19)$ for FDR, $13.69(95 \% \mathrm{CI}=$ 13.25-14.12) for SDR, and 19.71 (95\% CI = 19.17-20.26) for F/SDR. When examined by demographic characteristics, female, non-white, older, and less educated respondents reported higher numbers of FDR and SDR [21]. Four respondents were excluded from this analysis due to missing data related to education and personal cancer history.

The numbers of respondents with a FDR having a cancer of interest diagnosed at an early age were small. There were 11 with breast cancer, 3 with colorectal cancer, none with prostate cancer, and 1 with lung cancer diagnosed before the age of 40 . The number of respondents with FDR diagnosed between the age of 40 and 50 was 32 for breast cancer, 6 for colorectal cancer, 2 for prostate cancer, and 5 for lung cancer. Likewise, the number of respondents who reported more than 1 FDR with the same type of cancer was small (2 for breast, colorectal, prostate, and lung cancer each).

\section{Family History of Breast Cancer}

The adjusted prevalence estimates for reported family history of breast cancer among FDR, SDR, and F/SDR are shown in table 1 . Overall, $10.9 \%$ (95\% CI $=8.8-13.3 \%$ ) of respondents reported a family history of breast cancer in FDR, $17.9 \%$ (95\% CI $=15.4-20.1 \%)$ reported a family history of breast cancer in SDR and 26.4\% (95\% CI $=23.3-$ $29.8 \%$ ) reported a family history of breast cancer in F/SDR. While the reported prevalence of family history of breast cancer in FDR was similar for male and female respondents, it was higher in SDR for female respondents $(p=0.0007)$. The prevalence of a positive family history for breast cancer among FDR varied by respondents' race/ ethnicity $(\mathrm{p}=0.02)$, where non-Hispanic whites reported the highest prevalence. Increasing age of respondents was positively associated with higher reported prevalence of breast cancer history in FDR ( $\mathrm{p}$ for trend $=0.03$ ). Respondents with a post-graduate education reported more family history of breast cancer in both FDR and SDR compared with respondents with a college or less education, but the difference was not statistically significant. A personal history of any cancer was not associated with a higher likelihood of having a positive family history of breast cancer $(\mathrm{p}=0.96)$. In fact, $26.7 \%(95 \% \mathrm{CI}=23.3-$ $30.1 \%$ ) of respondents without a personal history of cancer reported having a history of breast cancer in F/SDR, compared with $23.4 \%$ (95\% CI $=14.2-32.7 \%)$ of those with such a history. The reported prevalence of a family history of breast cancer among FDR was highest in the lowest income group $(17.7 \%, 95 \% \mathrm{CI}=2.9-32.5 \%)$, but it was not statistically significantly different from the other income groups. Overall, family history of breast cancer in F/SDR did not vary significantly across demographic subgroups except for gender.

\section{Family History of Colorectal Cancer}

Altogether, the proportion of respondents reporting a family history of colorectal cancer was $5.1 \%$ (95\% CI = $3.9-6.7 \%), 12.3 \%(95 \% \mathrm{CI}=10.4-14.6 \%)$ and $16.5(95 \%$ $\mathrm{CI}=14.2-19.2 \%$ ) (table 1) in FDR, SDR and F/SDR, respectively. Similar to what was observed in breast cancer, female respondents reported a higher prevalence of 
Table 1. Adjusted prevalence ${ }^{1}$ of family history of breast, colorectal, prostate, and lung cancers by respondent characteristics

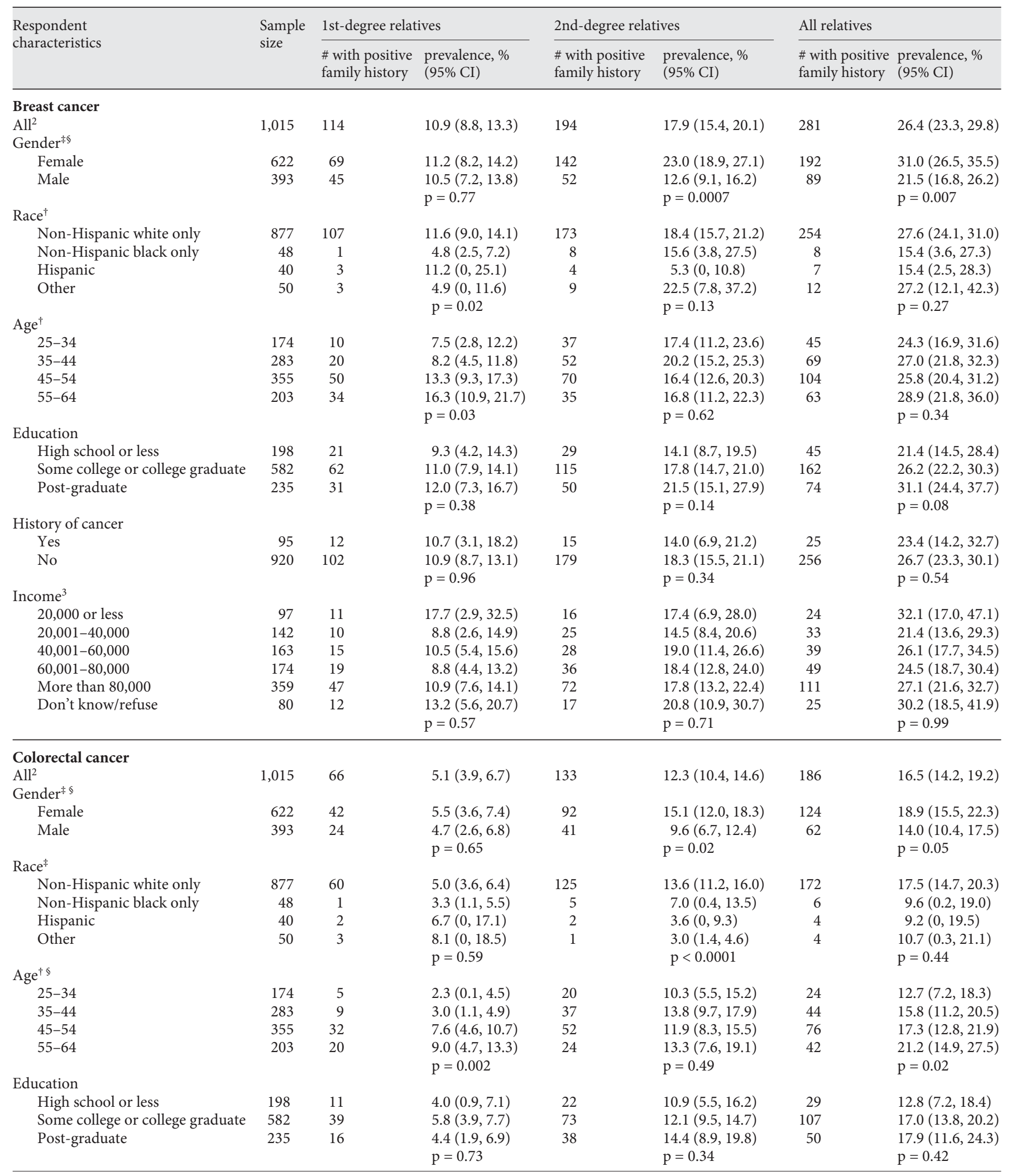


Table 1 (continued)

\begin{tabular}{|c|c|c|c|c|c|c|c|}
\hline \multirow{2}{*}{$\begin{array}{l}\text { Respondent } \\
\text { characteristics }\end{array}$} & \multirow{2}{*}{$\begin{array}{l}\text { Sample } \\
\text { size }\end{array}$} & \multicolumn{2}{|c|}{ 1st-degree relatives } & \multicolumn{2}{|c|}{2 nd-degree relatives } & \multicolumn{2}{|l|}{ All relatives } \\
\hline & & $\begin{array}{l}\text { \# with positive } \\
\text { family history }\end{array}$ & $\begin{array}{l}\text { prevalence, \% } \\
(95 \% \mathrm{CI})\end{array}$ & $\begin{array}{l}\text { \# with positive } \\
\text { family history }\end{array}$ & $\begin{array}{l}\text { prevalence, } \% \\
(95 \% \mathrm{CI})\end{array}$ & $\begin{array}{l}\text { \# with positive } \\
\text { family history }\end{array}$ & $\begin{array}{l}\text { prevalence, } \% \\
(95 \% \mathrm{CI})\end{array}$ \\
\hline \multicolumn{8}{|l|}{ History of cancer } \\
\hline Yes & 95 & 9 & $6.3(1.5,11.1)$ & 13 & $12.5(4.7,20.2)$ & 20 & $17.0(9.1,24.9)$ \\
\hline No & 920 & 57 & $\begin{array}{l}5.0(3.6,6.4) \\
p=0.61\end{array}$ & 120 & $\begin{array}{l}12.4(10.2,14.6) \\
p=0.98\end{array}$ & 166 & $\begin{array}{l}16.5(13.8,19.1) \\
p=0.89\end{array}$ \\
\hline \multicolumn{8}{|l|}{ Income $^{3}$} \\
\hline 20,000 or less & 97 & 4 & $2.5(0,5.6)$ & 7 & $9.1(2.0,16.1)$ & 10 & $10.4(3.1,17.7)$ \\
\hline $20,001-40,000$ & 142 & 4 & $2.2(0,4.6)$ & 16 & $9.5(4.0,14.9)$ & 19 & $10.6(5.2,15.9)$ \\
\hline $40,001-60,000$ & 163 & 13 & $6.0(2.7,9.2)$ & 20 & $10.9(4.3,17.6)$ & 31 & $15.9(9.1,22.8)$ \\
\hline $60,001-80,000$ & 174 & 9 & $4.2(1.2,7.2)$ & 25 & $14.0(7.7,20.4)$ & 34 & $18.3(11.1,25.4)$ \\
\hline More than 80,000 & 359 & 27 & $5.8(3.5,8.0)$ & 51 & $12.6(9.3,15.9)$ & 73 & $17.5(13.5,21.4)$ \\
\hline Don't know/refuse & 80 & 9 & $\begin{array}{l}8.9(2.5,15.3) \\
p=0.14\end{array}$ & 14 & $\begin{array}{l}17.6(7.8,27.5) \\
p=0.27\end{array}$ & 19 & $\begin{array}{l}23.1(12.8,33.4) \\
p=0.06\end{array}$ \\
\hline \multicolumn{8}{|l|}{ Prostate cancer } \\
\hline $\mathrm{All}^{2}$ & 1,015 & 73 & $7.0(5.2,9.4)$ & 83 & $8.0(6.4,9.9)$ & 135 & $13.2(10.8,16.2)$ \\
\hline \multicolumn{8}{|l|}{ Gender ${ }^{\ddagger}$} \\
\hline Female & 622 & 47 & $7.2(5.1,9.4)$ & 61 & $11.3(8.4,14.1)$ & 95 & $15.9(12.6,19.2)$ \\
\hline Male & 393 & 26 & $\begin{array}{l}6.8(3.1,10.5) \\
p=0.85\end{array}$ & 22 & $\begin{array}{l}5.3(3.1,7.6) \\
p=0.03\end{array}$ & 40 & $\begin{array}{l}10.5(6.7,14.3) \\
p=0.04\end{array}$ \\
\hline \multicolumn{8}{|l|}{ Race $^{\dagger \S}$} \\
\hline Non-Hispanic white only & 877 & 66 & $7.2(4.9,9.5)$ & 77 & $8.2(6.3,10.2)$ & 122 & $13.6(10.7,16.4)$ \\
\hline Non-Hispanic black only & 48 & 1 & $1.2(0.5,1.9)$ & 0 & & 1 & $1.1(0.4,1.7)$ \\
\hline Hispanic & 40 & 1 & $1.1(0.4,1.7)$ & 4 & $11.9(0,25.3)$ & 5 & $12.5(0,25.6)$ \\
\hline Other & 50 & 5 & $\begin{array}{l}14.0(0.1,27.9) \\
\mathrm{p}<0.0001\end{array}$ & 2 & $\begin{array}{l}7.0(0,17.7) \\
p=0.86\end{array}$ & 7 & $\begin{array}{l}20.5(4.6,36.5) \\
p<0.0001\end{array}$ \\
\hline \multicolumn{8}{|r|}{ P-0.000 } \\
\hline $25-34$ & 174 & 3 & $4.1(0,10.6)$ & 14 & $7.5(3.7,11.4)$ & 17 & $11.2(4.2,18.3)$ \\
\hline $35-44$ & 283 & 19 & $6.6(3.5,9.8)$ & 18 & $6.8(3.7,10.0)$ & 34 & $12.2(7.8,16.6)$ \\
\hline $45-54$ & 355 & 30 & $8.7(5.4,12.0)$ & 38 & $11.7(7.4,15.9)$ & 56 & $16.4(11.6,21.2)$ \\
\hline $55-64$ & 203 & 21 & $\begin{array}{l}9.3(5.2,13.4) \\
p=0.30\end{array}$ & 13 & $\begin{array}{l}6.9(2.4,11.5) \\
p=0.73\end{array}$ & 28 & $\begin{array}{l}13.0(7.4,18.6) \\
p=0.65\end{array}$ \\
\hline \multicolumn{8}{|l|}{ Education } \\
\hline High school or less & 198 & 13 & $5.4(1.7,9.0)$ & 10 & $6.1(0.7,11.4)$ & 22 & $11.0(4.3,17.6)$ \\
\hline Some college or college graduate & 582 & 41 & $7.4(4.6,10.2)$ & 51 & $8.4(5.9,10.9)$ & 79 & $13.6(9.9,17.3)$ \\
\hline Post-graduate & 235 & 19 & $\begin{array}{l}7.3(3.6,11.0) \\
p=0.62\end{array}$ & 22 & $\begin{array}{l}9.9(5.4,14.3) \\
p=0.55\end{array}$ & 34 & $\begin{array}{l}14.0(8.8,19.1) \\
p=0.71\end{array}$ \\
\hline \multicolumn{8}{|l|}{ History of cancer } \\
\hline Yes & 95 & 8 & $8.9(2.4,15.4)$ & 11 & $11.6(3.3,19.8)$ & 17 & $17.7(8.1,27.3)$ \\
\hline No & 920 & 65 & $\begin{array}{l}6.8(4.8,8.9) \\
p=0.50\end{array}$ & 72 & $\begin{array}{l}8.0(6.2,9.8) \\
p=0.37\end{array}$ & 118 & $\begin{array}{l}12.8(10.3,15.3) \\
p=0.24\end{array}$ \\
\hline \multicolumn{8}{|l|}{ Income $^{3}$} \\
\hline 20,000 or less & 97 & 5 & $6.5(0,14.6)$ & 2 & $3.5(0,9.1)$ & 7 & $9.0(0.2,17.9)$ \\
\hline $20,001-40,000$ & 142 & 10 & $6.7(1.6,11.9)$ & 12 & $9.0(2.7,15.3)$ & 21 & $14.3(5.6,23.0)$ \\
\hline $40,001-60,000$ & 163 & 8 & $4.3(0.9,7.8)$ & 7 & $5.0(1.5,8.5)$ & 14 & $8.0(4.0,12.1)$ \\
\hline $60,001-80,000$ & 174 & 17 & $11.2(2.3,20.0)$ & 26 & $16.0(10.1,21.9)$ & 34 & $22.3(13.0,31.7)$ \\
\hline More than 80,000 & 359 & 24 & $5.7(3.1,8.2)$ & 32 & $7.6(4.5,10.7)$ & 48 & $11.8(7.8,15.7)$ \\
\hline Don't know/refuse & 80 & 9 & $\begin{array}{l}10.3(3.1,17.4) \\
p=0.96\end{array}$ & 4 & $\begin{array}{l}5.4(0.1,10.7) \\
p=0.27\end{array}$ & 11 & $\begin{array}{l}13.0(5.3,20.6) \\
p=0.48\end{array}$ \\
\hline \multicolumn{8}{|l|}{ Lung cancer } \\
\hline $\mathrm{All}^{2}$ & 1,015 & 75 & $6.4(4.9,8.3)$ & 190 & $18.3(15.7,21.2)$ & 244 & $22.9(20.4,25.7)$ \\
\hline Gender & & & & & & & \\
\hline Female & 622 & 49 & $6.4(4.2,8.7)$ & 123 & $20.1(16.6,23.6)$ & 156 & $24.1(20.6,27.6)$ \\
\hline Male & 393 & 26 & $\begin{array}{l}6.3(3.8,8.8) \\
p=0.95\end{array}$ & 67 & $\begin{array}{l}16.4(12.1,20.7) \\
p=0.21\end{array}$ & 88 & $\begin{array}{l}21.7(17.3,26.1) \\
p=0.43\end{array}$ \\
\hline Race & & & & & & & \\
\hline Non-Hispanic white only & 877 & 61 & $5.6(4.0,7.3)$ & 174 & $19.6(16.6,22.6)$ & 215 & $23.2(20.3,26.0)$ \\
\hline Non-Hispanic black only & 48 & 4 & $12.8(0,27.5)$ & 5 & $13.9(0,30.7)$ & 9 & $26.0(7.1,44.9)$ \\
\hline Hispanic & 40 & 5 & $8.3(0,16.7)$ & 2 & $3.5(0,9.4)$ & 7 & $12.4(1.0,23.8)$ \\
\hline Other & 50 & 5 & $\begin{array}{l}11.1(1.2,21.1) \\
p=0.43\end{array}$ & 9 & $\begin{array}{l}16.0(3.7,28.2) \\
p=0.56\end{array}$ & 13 & $\begin{array}{l}25.8(11.4,40.1) \\
p=0.50\end{array}$ \\
\hline
\end{tabular}


Table 1 (continued)

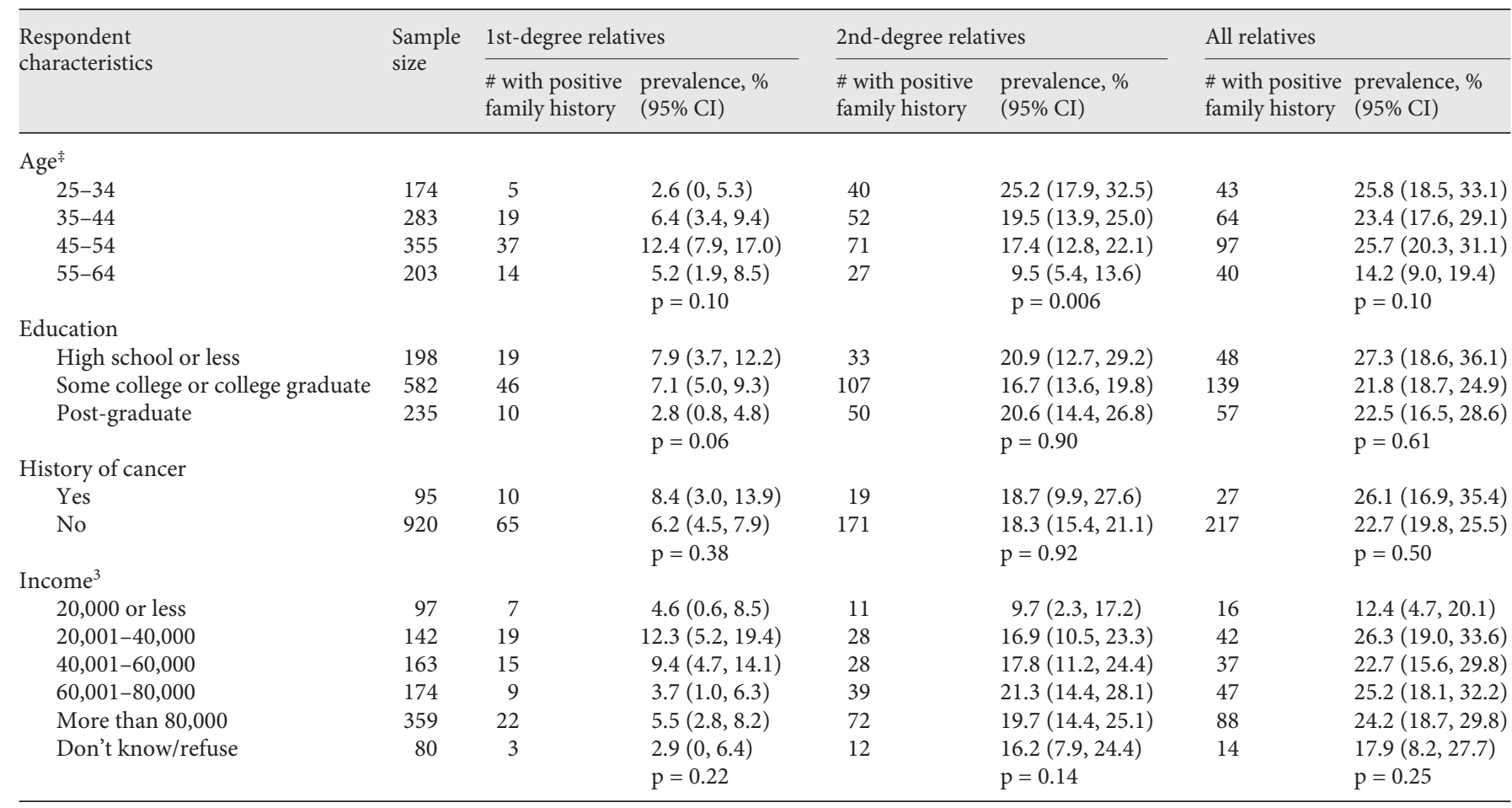

${ }^{1}$ Adjusted using logistic regression with all of the variables in the table included as covariates. ${ }^{2}$ Overall prevalence is unadjusted. ${ }^{3}$ Don't know/refuse group was not included in models for trend. ${ }^{\dagger}$ Global Wald $\mathrm{F}$ test for nominal variables and trend test for ordinal variables, $\mathrm{p}$ value for FDR $\leq 0.05$. ${ }^{\ddagger} \mathrm{Glob}$ al Wald $\mathrm{F}$ test for nominal variables and trend test for ordinal variables, $\mathrm{p}$ value for $\mathrm{SDR} \leq 0.05 .{ }^{\S}$ Global Wald $\mathrm{F}$ test for nominal variables and trend test for ordinal variables, $\mathrm{p}$ value for $\mathrm{F} / \mathrm{SDR} \leq 0.05$.

colorectal cancer in SDR $(15.1 \%, 95 \% \mathrm{CI}=12.0-18.3 \%)$ compared with male respondents $(9.6 \%, 95 \% \mathrm{CI}=6.7-$ $12.4 \%)(\mathrm{p}=0.02)$. Among the $4 \mathrm{racial} / \mathrm{ethnic}$ groups, nonHispanic white and non-Hispanic black reported lower prevalence of colorectal cancer in FDR and higher prevalence in SDR, but the differences were only statistically significant for the comparisons among SDR $(p<0.0001)$. There was a statistically significant positive association between increasing age and reported prevalence of colorectal cancer in FDR ( $\mathrm{p}$ for trend $=0.002$ ) and in $\mathrm{F} / \mathrm{SDR}$ ( $\mathrm{p}$ for trend $=0.02$ ). Increasing education levels were associated with increasing reported prevalence of colorectal cancer in SDR; however, the trend did not reach statistically significant level. The presence of a personal history of any cancer was not associated with reported family history of colorectal cancer in either FDR or SDR. No significant variation by income levels was observed for either FDR or SDR.

\section{Family History of Prostate Cancer}

Table 1 shows the adjusted prevalence of family history of prostate cancer as reported by FHS participants. Overall, $7.0 \%$ (95\% CI $=5.2-8.4 \%)$ of the respondents reported a family history of prostate cancer in FDR, 8.0\% $(95 \% \mathrm{CI}=6.4-9.9 \%)$ reported a family history of prostate cancer in SDR and 13.2 (95\% CI $=10.8-16.2 \%)$ reported a family history of prostate cancer in F/SDR. Female participants reported a higher prevalence of prostate cancer in $\operatorname{SDR}(11.3 \%, 95 \% \mathrm{CI}=8.4-14.1 \%$ vs. $5.3 \%, 95 \% \mathrm{CI}=$ $3.1-7.6 \%, p=0.003)$ but not in FDR. Non-Hispanic blacks and Hispanics reported a very low prevalence of prostate cancer in FDR, and no history of prostate cancer was reported in SDR of non-Hispanic blacks. While increasing age was associated with higher prevalence of family history of prostate cancer among FDR, the overall trend was not statistically significant. Participants with a 'high school or less' education level reported a lower prevalence of family history of prostate cancer, but the trend was not 
statistically significantly different for any relatedness category. Participants with a personal history of any cancer reported a statistically nonsignificant higher prevalence of prostate cancer among both FDR and SDR compared with those without a cancer history. Income did not correlate with prevalence of family history of prostate cancer.

\section{Family History of Lung Cancer}

Overall, 6.4\% (95\% CI $=4.9-8.3 \%)$ of respondents reported a family history of lung cancer in FDR, 18.3\% (95\% $\mathrm{CI}=15.7-21.2 \%)$ in SDR and $22.9 \%$ (95\% CI $=20.4-25.7 \%)$ in F/SDR. Similar to the findings for all other major cancers examined in this study, female respondents reported a higher prevalence of lung cancer in SDR $(20.1,95 \% \mathrm{CI}=$ $16.6-23.6 \%)$ compared with male respondents $(16.4 \%$, $95 \% \mathrm{CI}=12.1-20.7 \%)$; however, the different prevalence in family history of lung cancer by gender did not reach a statistically significant level $(\mathrm{p}=0.21)$. The reported prevalence of family history of lung cancer varied by race/ ethnicity, but the difference was not statistically significant among the subgroups. There was an inverse correlation between increasing age and reported prevalence of a family history of lung cancer in SDR ( $p$ for trend $=0.006$ ) but not in FDR. Respondents with higher education levels reported lower prevalence of family history of lung cancer among FDR, but the trend was not statistically significant $(p=0.06)$. Income level did not appear to be associated with a family history of lung cancer; however, respondents in the lowest income level reported a very low prevalence, particularly in SDR compared with the other levels. A personal history of any cancer was not associated with the reported prevalence of lung cancer in FDR or SDR.

\section{Discussion}

In this study, we reported the prevalence of family history of breast, colorectal, prostate, and lung cancer in a population-based survey in CT. There were differences in the reported prevalence of family history of specific cancers by sex, age and race/ethnicity. The most consistently observed difference was that the reported prevalence of family history for all 4 types of cancer examined was higher among SDR of female respondents than among SDR of male respondents.

Overall, the prevalence of family history of breast cancer among FDR in our study is similar to that reported by Pinsky et al. [18], but is higher than that in some other

Family Cancer History Prevalence studies, which reported a prevalence between 4 and $8 \%$ $[17,19]$. Most of the prior studies reported on prevalence of family history only among FDR. In our study, the reported prevalence of a family history of breast, colorectal, prostate, and lung cancer in SDR was substantial and varied by certain respondent characteristics. The reported prevalence of a family history of prostate cancer in SDR is similar to the prevalence in FDR and is somewhat lower than the prevalence in SDR for the other cancers. This could be due to lack of knowledge regarding prostate cancer in more distant relatives; however, it is possible that the prevalence of prostate cancer was indeed lower for SDR as prostate cancer screening was not routinely done at the time when the older generation (i.e. the grandfathers) were alive. It is important to ascertain family history in SDR in addition to FDR because, although cancer risk estimation has been based mainly on family history among FDR [8, 9], family history among SDR may be informative in cancer risk assessment, particularly for sexspecific cancers, such as breast and prostate.

In our study, the prevalence of reported family history of breast, colorectal, prostate, and lung cancer among FDR was similar between male and female respondents; however, female respondents reported more family history of these cancers among SDR than male respondents. In contrast, in both the Prostate, Lung, Colorectal, and Ovarian Cancer Screening Trial [18] and the National Health Interview Survey [19], female respondents reported a larger number of cancer cases in FDR compared with male participants. Without verifying the true prevalence of cancer among all relatives of respondents, we cannot determine if the difference in cancer history reported in SDR is due to overreporting by female respondents or to underreporting by male respondents. Previous studies have shown that females were slightly more accurate than males in reporting history of cancers among their FDR $[28,29]$. Furthermore, the rate of overreporting a family cancer history has been found to be low [30]. Thus, although we did not confirm the true prevalence of family history of cancer in CT in this current report, it is likely that female respondents were more aware of cancer history in their SDR than male respondents.

Reported family cancer history prevalence appears to vary by race/ethnicity for breast cancer. The numbers of all affected relatives reported for the other cancer sites were too small to draw any conclusions. A few studies have shown that the reported rates of family cancer history are higher for whites compared with other racial/ ethnic groups $[18,19]$. Our findings show that the prevalence of family history among all relatives for breast, 
colorectal and prostate cancer as reported is higher among whites compared with non-Hispanic blacks and Hispanics. While for breast cancer, this difference might reflect variations in breast cancer incidence rate by race/ ethnicity in the general population [31], the same does not apply for colorectal or prostate cancer since blacks have the highest incidence rate for these cancers in the general population. Lower rates of reported family history of cancer in blacks compared with whites have previously been suggested to be due to underreporting [18]. In a study investigating racial/ethnic and gender differences in family cancer history knowledge among patients referred to a high-risk colon cancer clinic, blacks were found to have less knowledge of their paternal family history of cancer than whites [32]. Whether these variations in family cancer history knowledge by race/ethnicity were potentially related to cultural differences in willingness to discuss cancer-related issues with family members [33], particularly with relatives more distant than first-degree, is unclear. However, the number of non-white respondents in this study was quite small, resulting in unstable reported prevalence by race/ethnicity.

Higher education level was associated with increasing prevalence of family history of breast, colorectal and prostate cancer. While education is a surrogate for socioeconomic status, which has been suggested to be associated with breast and colorectal cancer incidence rates [34, 35], the positive association observed here might be partly due to greater cancer risk awareness in participants with a higher education level.

Although it would have been helpful to evaluate the prevalence of respondents with a family history of cancer suggestive of higher risk (i.e. young age at diagnosis and/ or multiple relatives with the same type of cancer or the constellation of cancers that are seen in certain hereditary cancer syndromes), the number of respondents with a FDR diagnosed with breast, colorectal, prostate, or lung cancer before the age of 50 was small, except for breast cancer, and would thus have yielded unstable estimates. For each type of cancer examined, only 2 respondents reported having more than one relative with that cancer. We were not able to distinguish maternal SDR from paternal SDR and thus could not accurately ascertain the number of respondents with multiple FDR and SDR from the same lineage (i.e. a respondent with a mother and a paternal aunt with breast cancer would not be considered having multiple affected relatives).

This study has several strengths. First, this is a unique population-based survey that provides state-based public health statistics on the prevalence of family history of ma- jor cancers in both FDR and SDR. While larger sample sizes are needed to detect rare hereditary cancer syndromes, estimates such as those in this study adequately describe prevalence in average to moderate risk groups. Second, this survey also collected data on demographic factors, which allowed for adjustment for variability in prevalence estimates and confirmation of previous findings that suggest sociocultural differences in reporting preferences or awareness of family history. Furthermore, concurrent collection of extensive family structure in this survey may have reduced the likelihood of respondents forgetting to report cancers in all relatives. Finally, we developed and applied a systematic approach to evaluating and classifying the family history information that was reported to us, in an effort to exclude reports that were not sufficiently clear to reliably include them, and to identify the details related to cancer report misclassification.

There are also some limitations to the data. First, the data regarding family cancer history were abstracted from unvalidated verbatim responses provided by the respondents. Thus, the prevalence of cancer in relatives may be inaccurate due to over- or underreporting. We will have the opportunity to assess this bias quantitatively when we complete the analysis comparing reported diagnoses to data ascertained through several sources, including the Connecticut Tumor Registry for the same individuals. Second, the CT population in this study is not representative of CT or the U.S. overall, due to the small proportions of blacks and Hispanics. When the FHS demographic distribution was compared with states and national distribution from the 2001 U.S. Current Population Surveys, it was apparent that individuals of minority and low socioeconomic status were underrepresented in this study population. Our study results are, therefore, most generalizable to white population of CT. Finally, since the eligibility criteria restricted the sample to subjects between ages 25 and 64, the results might not be generalizable outside this age range.

In summary, we documented a substantial family history prevalence for 4 of the most common adult solid tumors. In addition, our study shows that the reported prevalence of family history of common cancers varies by specific respondent characteristics, most notably gender, age and race/ethnicity. We speculate that some of this difference is likely due to different degrees of family history awareness, particularly when it comes to cancer history among SDR. Obtaining an accurate family history, including the age at diagnosis for affected relatives and the exact relationship to the reporting individual, is an im- 
portant part in accurate risk assessment for several types of cancers [2-9] and can lead to adjustments in screening recommendations. Additional studies are needed to evaluate what tools can be used to enhance awareness and promote accurate reporting.

\section{Acknowledgements}

This research was funded in part by the Intramural Research Program of the National Cancer Institute, National Institutes of Health, and supported by contract \# N01-PC-95039 with Westat, Inc. The authors have no conflict of interest or financial disclosures to report.

\section{References}

1 Jemal A, Siegel R, Ward E, Hao Y, Xu J, Murray T, Thun MJ: Cancer Statistics, 2008. CA Cancer J Clin 2008;58:71-96.

-2 Dong C, Hemminki K: Modification of cancer risks in offspring by sibling and parental cancers from 2,112,616 nuclear families. Int J Cancer 2001;92:144-150.

- 3 Randi G, Pelucchi C, Negri E, Talamini R, Galeone C, Franceschi S, Vecchia CL: Family history of urogenital cancers in patients with bladder, renal cell and prostate cancers. Int J Cancer 2007;121:2748-2752.

4 Poole CA, Byers T, Calle EE, Bondy J, Fain P, Rodriguez C: Influence of a family history of cancer within and across multiple sites on patterns of cancer mortality risk for women. Am J Epidemiol 1999;149:454-462.

5 Kerber RA, O'Brien E: A cohort study of cancer risk in relation to family histories of cancer in the Utah population database. Cancer 2005; 103:1906-1915.

-6 McWilliams RR, Rabe KG, Olswold C, Andrade MD, Petersen GM: Risk of malignancy in first-degree relatives of patients with pancreatic carcinoma. Cancer 2005; 104:388394.

7 Offit K, Brown K: Quantitating familial cancer risk: a resource for clinical oncologists. J Clin Oncol 1994;12:1724-1736.

$\checkmark 8$ Noe M, Schroy P, Demierre MF, Babayan R, Geller A: Increased cancer risk for individuals with a family history of prostate cancer, colorectal cancer, and melanoma and their associated screening recommendations and practices. Cancer Causes Control 2008;19: $1-12$.

9 Chen YC, Page JH, Chen R, Giovannucci E: Family history of prostate and breast cancer and the risk of prostate cancer in the PSA era. Prostate 2008;68:1582-1591

10 Garber JE, Offit K: Hereditary cancer predisposition syndromes. J Clin Oncol 2005; 23:276-292.

11 US Preventive Services Task Force: Guide to Clinical Preventive Services. Cancer. Available at http://www.ahrq.gov/clinic/cps3dix. htm\#cancer (accessed on 5/14/2009).
Smith RA, Cokkinides V, Eyre HJ: American Cancer Society guidelines for the early detection of cancer, 2006. CA Cancer J Clin 2006;56:11-25.

13 Yoon PW, Scheuner MT, Khoury MJ: Research priorities for evaluating family history in the prevention of common chronic diseases. Am J Prev Med 2003;24:128-135.

14 Guttmacher AE, Collins FS, Carmona RH: The family history - More important than ever. N Engl J Med 2004;351:2333-2336.

$\checkmark 15$ Yoon PW, Scheuner MT, Peterson-Oehlke KL, Gwinn M, Faucett A, Khoury MJ: Can family history be used as a tool for public health and preventive medicine? Genet Med 2002:4:304-310

16 Hemminki K, Sundquist J, Bermejo JL: How common is familial cancer? Ann Oncol 2008;19:163-167.

17 Johnson N, Lancaster T, Fuller A, Hodgson $\mathrm{SV}$ : The prevalence of a family history of cancer in general practice. Fam Pract 1995;12: 287-289.

18 Pinsky PF, Kramer BS, Reding D, Buys S: Reported family history of cancer in the Prostate, Lung, Colorectal, and Ovarian Cancer Screening Trial. Am J Epidemiol 2003;157: 792-799.

19 Ramsey SD, Yoon P, Moonesinghe R, Khoury MJ: Population-based study of the prevalence of family history of cancer: implications for cancer screening and prevention. Genet Med 2006;8:571-575.

20 Murff HJ, Peterson NB, Greevy R, Zheng W: Impact of patient age on family cancer history. Genet Med 2006;8:438-442.

21 Garceau A, Wideroff L, McNeel T, Dunn M, Graubard BI: Population estimates of extended family structure and size. Community Genet 2008;11:331-342.

22 Levy PS, Lemeshow S: Sampling of Populations: Methods and Applications, ed 3. New York, John Wiley and Sons, Inc., 1999.

23 CASRO: Council of American Survey Organizations. On the definition of response rates. New York, Council of American Survey Organizations, 1982.

24 Fritz A, Percy C, Jack A, Shanmugarathan S, Sobin L, Parkin DM, Whelan S: International Classification of Diseases for Oncology (ICD-O-3). Geneva, World Health Organization, 2000.
25 Rust KF, Rao JN: Variance estimation for complex surveys using replication techniques. Stat Methods Med Res 1996;5:283310 .

26 Korn EL, Graubard B: Analysis of Health Surveys. New York, John Wiley and Sons, 1999.

27 Graubard BI, Korn EL: Predictive margins with survey data. Biometrics 1999;55:652659.

28 Kerber RA, Slattery ML: Comparison of selfreported and database-linked family history of cancer data in a case-control study. Am J Epidemiol 1997;146:244-248.

29 Glanz K, Grove J, Le Marchand L, Gotay C: Underreporting of family history of colon cancer: correlates and implications. Cancer Epidemiol Biomarkers Prev 1999;8:635-639.

30 Ziogas A, Anton-Culver H: Validation of family history data in cancer family registries. Am J Prev Med 2003;24:190-198.

31 Horner M, Ries L, Krapcho M, Neyman N, Aminou R, Howlader N, Altekruse S, Feuer E, Huang L, Mariotto A, Miller B, Lewis $D$, Eisner $M$, Stinchcomb D, Edwards B (eds): SEER Cancer Statistics Review, 19752006, National Cancer Institute, Bethesda, MD. Available at http://seer.cancer.gov/csr/ 1975 2006/index.html, based on November 2008 SEER data submission, posted to the SEER web site, 2009.

- 32 Kupfer SS, McCaffrey S, Kim KE: Racial and gender disparities in hereditary colorectal cancer risk assessment: the role of family history. J Cancer Educ 2006;21(suppl 1):32-36.

33 Matthews AK, Cummings S, Thompson S, Wohl V, List M, Olopade OI: Genetic testing of African Americans for susceptibility to inherited cancers: use of focus groups to determine factors contributing to participation. J Psychosoc Oncol 2000;18:1-19.

34 Vainshtein J: Disparities in breast cancer incidence across racial/ethnic strata and socioeconomic status: a systematic review. J Natl Med Assoc 2008;100:833-839.

- 35 van Loon A, van den Brandt P, Golbohm R: Socioeconomic status and colon cancer incidence: a prospective cohort study. Br J Cancer 1995;71:882-887. 